\title{
Technical Note: Intercomparison of ILAS-II version 2 and 1.4 trace species with MIPAS-B measurements
}

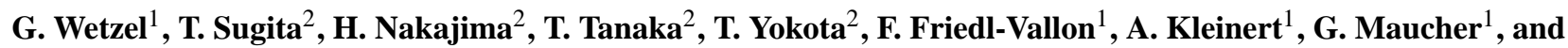 \\ H. Oelhaf ${ }^{1}$ \\ ${ }^{1}$ Institut für Meteorologie und Klimaforschung (IMK), Forschungszentrum Karlsruhe, Karlsruhe, Germany \\ ${ }^{2}$ National Institute for Environmental Studies, Tsukuba, Japan
}

Received: 27 September 2007 - Published in Atmos. Chem. Phys. Discuss.: 22 November 2007

Revised: 25 January 2008 - Accepted: 31 January 2008 - Published: 28 February 2008

\begin{abstract}
The Improved Limb Atmospheric Spectrometer (ILAS)-II sensor aboard the Japanese ADEOS-II satellite was launched into its sun-synchronous orbit on 14 December 2002 and performed solar occultation measurements of trace species, aerosols, temperature, and pressure in the polar stratosphere until 25 October 2003. Vertical trace gas profiles obtained with the balloon version of the Michelson Interferometer for Passive Atmospheric Sounding (MIPASB) provide one of the sparse data sets for validating ILAS-II version 2 and 1.4 data. The MIPAS-B limb emission spectra were collected on 20 March 2003 over Kiruna (Sweden, $68^{\circ} \mathrm{N}$ ) at virtually the same location that has been sounded by ILAS-II about $5.5 \mathrm{~h}$ prior to the sampling of MIPAS-B. The intercomparison of the new ILAS-II version 2 (Northern Hemispheric sunrise) data to MIPAS-B vertical trace gas profiles shows a good to excellent agreement within the combined error limits for the species $\mathrm{O}_{3}, \mathrm{~N}_{2} \mathrm{O}, \mathrm{CH}_{4}, \mathrm{H}_{2} \mathrm{O}$ (above $21 \mathrm{~km}), \mathrm{HNO}_{3}, \mathrm{ClONO}_{2}$, and $\mathrm{CFC}-11\left(\mathrm{CCl}_{3} \mathrm{~F}\right)$ in the compared altitude range between 16 and $31 \mathrm{~km}$ such that these data appear to be very useful for scientific analysis. With regard to the previous version 1.4 ILAS-II data, significant improvements in the consistency with MIPAS-B are obvious especially for the species $\mathrm{CH}_{4}$ and $\mathrm{H}_{2} \mathrm{O}$, but also for $\mathrm{O}_{3}, \mathrm{HNO}_{3}, \mathrm{ClONO}_{2}, \mathrm{NO}_{2}$, and $\mathrm{N}_{2} \mathrm{O}_{5}$. However, comparing gases like $\mathrm{NO}_{2}, \mathrm{~N}_{2} \mathrm{O}_{5}$, and $\mathrm{CFC}-12\left(\mathrm{CCl}_{2} \mathrm{~F}_{2}\right)$ exhibits only poor agreement with MIPAS-B such that these species cannot be assumed to be validated at the present time.
\end{abstract}

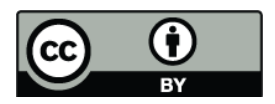

Correspondence to: G. Wetzel (gerald.wetzel@imk.fzk.de)

\section{Introduction}

Satellite measurements are important for monitoring the atmosphere within the context of naturally and anthropogenically induced climate changes since atmospheric parameters can be derived from these remote sensing measurements over large areas of the Earth. The second version of the Japanese Advanced Earth Observing Satellite (ADEOS-II) was launched on 14 December 2002 and operated sporadically between January and March 2003, followed by a continuous and routinely operation between 2 April and 25 October 2003. A malfunction of the solar power subsystem prevented a further operation after this date.

Apart from satellite observations, balloon-borne measurements are a valuable tool to obtain distributions of a large number of trace species with sufficiently high vertical resolution over most of the stratospheric altitude region. Due to the quasi-Lagrangian observation, long integration times are possible which significantly reduce the influence of noise in the recorded spectra. Since the number of balloon launches is restricted due to logistical and financial constraints the quality of the spatial and temporal coincidence between the satellite measurement and the balloon observation is a crucial issue.

A flight of the balloon version of the Michelson Interferometer for Passive Atmospheric Sounding (MIPAS-B) instrument was carried out from Kiruna (Sweden, $68^{\circ} \mathrm{N}$ ) on 20/21 March 2003 as part of a validation campaign for the chemistry instruments MIPAS, GOMOS, and SCIAMACHY aboard the environmental satellite ENVISAT (see, e.g., Wetzel et al., 2007). Owing to the long duration of this flight, a good match with observations of the Improved Limb Atmospheric Spectrometer (ILAS)-II sensor aboard the ADEOS-II satellite could be managed. Limb emission spectra were observed by MIPAS-B at virtually the same location inside the

Published by Copernicus Publications on behalf of the European Geosciences Union. 
polar vortex that has been sounded by ILAS-II about $5.5 \mathrm{~h}$ prior to the sampling of MIPAS-B. The mean horizontal distance of the observed tangent points of both sensors was less than $100 \mathrm{~km}$. In this paper, analysed data (version 1.4 and 2) of ILAS-II are compared to observations with the MIPAS-B instrument. The paper provides an assessment of these new ILAS-II version 2 data following up the earlier presented validation of version 1.4 data (Wetzel et al., 2006).

\section{Instruments and data analysis}

ILAS-II was one of five sensors aboard the ADEOS-II satellite and was designed similarly to its predecessor (Sasano et al., 1999; Nakajima et al., 2006) using the solar occultation technique. Four spectrometers covered the infrared (3-13 $\mu \mathrm{m}$; including a narrow high-resolution channel for the detection of $\mathrm{ClONO}_{2}$ ) and the near visible region $(753-784 \mathrm{~nm})$ with a spectral resolution from $0.129 \mu \mathrm{m}$ up to $0.15 \mathrm{~nm}$. Observations were confined to high-latitudes $\left(57^{\circ} \mathrm{N}\right.$ to $73^{\circ} \mathrm{N}$ and $64^{\circ} \mathrm{S}$ to $90^{\circ} \mathrm{S}$ ) because of the geometrical relation of the solar occultation events with the sunsynchronous orbit. Measurements were performed approximately 14 times daily in each hemisphere. First sporadic soundings were carried out in January 2003. Routine measurements were taken from April to October 2003. Vertical profiles of species related to ozone chemistry, including $\mathrm{O}_{3}$, $\mathrm{HNO}_{3}, \mathrm{NO}_{2}, \mathrm{~N}_{2} \mathrm{O}, \mathrm{CH}_{4}, \mathrm{H}_{2} \mathrm{O}, \mathrm{CFC}-11\left(\mathrm{CCl}_{3} \mathrm{~F}\right), \mathrm{CFC}-12$ $\left(\mathrm{CCl}_{2} \mathrm{~F}_{2}\right), \mathrm{ClONO}_{2}$, and $\mathrm{N}_{2} \mathrm{O}_{5}$, as well as aerosol extinction coefficients at $780 \mathrm{~nm}$, temperature, and pressure can be derived from the measured spectra. Retrieval calculations were performed with an onion-peeling algorithm with a multiparameter least squares fitting procedure (Yokota et al., 2002). A total error is calculated as the root sum squares of the internal and external errors at each profile altitude. Internal errors are estimated from the final residuals in the spectral non-linear least squares fitting. External errors comprise uncertainties in the non-gaseous correction due to aerosols and temperature uncertainties. Spectroscopic parameters were chosen from the high-resolution transmission molecular absorption database (HITRAN; Rothman et al., 2003, 2005). The retrieval grid was set to $1 \mathrm{~km}$, while the typical vertical resolution ranges between 1.3 and $2.9 \mathrm{~km}$.

As compared to version 1.4 data the following improvements have been applied for processing version 2: a transmittance correction has been adopted taking into account the changing spectrometer signal due to the distortion of the entrance slit by solar heat energy during the sunrise occultation events (Northern Hemisphere). A new tangent height registration method was applied using information of the gimbal mirror angle instead of the sun edge sensor method used for the version 1.4 data which was affected by the occurrence of polar stratospheric clouds (PSCs) in the lower stratosphere (Tanaka et al., 2007). Another major difference between ILAS-II version 2 and version 1.4 data is the use of HITRAN
2004 (Rothman et al., 2005) line parameters instead of HITRAN 2k (Rothman et al., 2003).

The balloon-borne Fourier transform spectrometer MIPAS-B is a limb-emission sounder which covers the mid-infrared spectral range (4 to $14 \mu \mathrm{m}$ ) and operates at cryogenic temperatures. Besides a high performance and flexibility of the pointing system the suitability of MIPAS-B to validate instruments like ILAS-II is based mainly on its high spectral resolution (about $0.07 \mathrm{~cm}^{-1}$ after apodization) allowing the separation of individual spectral lines from continuum-like emissions in combination with a high radiometric accuracy. A comprehensive overview and description of the instrument is given by Friedl-Vallon et al. (2004) and references therein. A MIPAS-B flight was carried out on 20/21 March 2003 from Kiruna (Sweden, $68^{\circ} \mathrm{N}$ ), dedicated mainly to ENVISAT validation tasks (see, e.g., Cortesi et al., 2007; Höpfner et al., 2007; Ridolfi et al., 2007; Wang et al., 2007; Wetzel et al., 2007). The flight duration of more than $15 \mathrm{~h}$ from 18:22 UTC (20 March) to 09:38 UTC (21 March) also permitted a good match of the sunrise measurement of the ILAS-II sensor aboard ADEOS-II. Radiance spectra were observed at the same location ILAS-II had measured about $5.5 \mathrm{~h}$ prior to the sampling by MIPAS-B. Both instruments measured nearly the same air masses inside the polar vortex over a wide altitude range in the absence of polar stratospheric clouds (Wetzel et al., 2006). The mean horizontal distance of the observed tangent points of both sensors was less than $100 \mathrm{~km}$ in the overlapping altitude region. Backward trajectory calculations have shown that air masses measured by MIPAS-B were within a $500 \mathrm{~km}$ horizontal distance to ILAS-II at the time of the ILAS-II observation. MIPAS-B measures all atmospheric parameters ILAS-II is covering. Retrieval calculations of atmospheric target parameters were performed with a least squares fitting algorithm using analytical derivative spectra calculated by the Karlsruhe Optimized and Precise Radiative transfer Algorithm (KOPRA; Stiller et al., 2002; Höpfner et al., 2002). A Tikhonov-Phillips regularization approach was applied which was constrained with respect to the form of an a priori profile. The resulting vertical resolution for all intercomparison species lies between about 1.5 and $3 \mathrm{~km}$ and is therefore comparable to the vertical resolution of ILAS-II. The error estimation includes random noise as well as the mutual influence (covariance effects) of the fitted parameters, temperature errors, and line of sight inaccuracies. Spectroscopic parameters chosen for the MIPAS-B retrieval are consistent with the database taken for the ILAS-II data analysis. More details of the MIPAS-B data analysis is given by Wetzel et al. (2006) and references therein.

\section{Profile comparison of trace species}

In this section, profiles of trace gases measured by MIPAS-B are compared to ILAS-II version 1.4 and 2 data. To account 


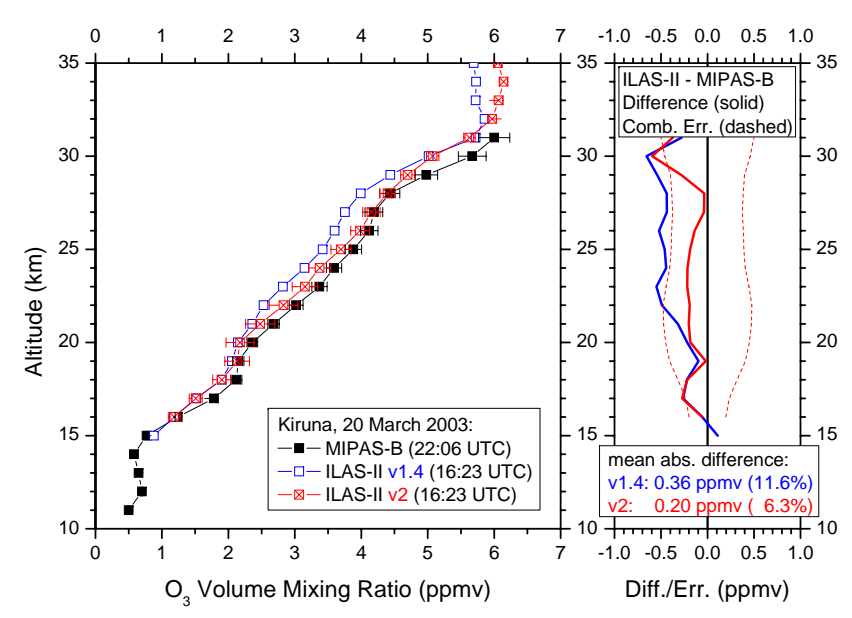

Fig. 1. Comparison of $\mathrm{O}_{3}$ profiles as measured by MIPAS-B and ILAS-II (data versions 1.4 (v1.4) and 2 (v2)) on 20 March 2003 above northern Scandinavia together with differences and combined total errors. Mean difference values are calculated over all coincident altitudes.

for the small temporal and spatial mismatch of both observations, ILAS-II measured quantities were linearly interpolated to the potential temperature levels corresponding to the MIPAS-B altitude grid. Volume mixing ratio (VMR) differences of measured trace species are displayed together with the combined total errors of both instruments within a $95 \%$ confidence limit. They have been calculated by the root sum squares of the total errors of each instrument neglecting spectroscopic inaccuracies since the same spectroscopic database and the same molecular bands have been used during the retrieval process of both instruments. The comparison between the VMR difference and the combined total error of the two instruments is appropriate to identify unexplained biases in the ILAS-II data. These biases are considered to be significant when they exceed the combined error limits.

\subsection{Ozone}

The results for the comparison of the trace species ozone are shown in Fig. 1. The overall agreement between ILAS-II and MIPAS-B measured quantities is found to be quite good. The shapes of all measured profiles are very similar. The clear negative bias in the previous ILAS-II version 1.4 data is reduced significantly in the newer data version. Except for the region around $30 \mathrm{~km}$, the differences calculated for the new version 2 data are clearly within the combined error limits and the mean absolute difference averaged over all coincident altitudes amounts to only $6 \%$.

\subsection{Nitrous oxide and methane}

Profile comparisons of $\mathrm{N}_{2} \mathrm{O}$ and $\mathrm{CH}_{4}$ are considered together since the behaviour of these long-lived trace gases in the stratosphere in terms of transport and lifetime is similar. Fig-

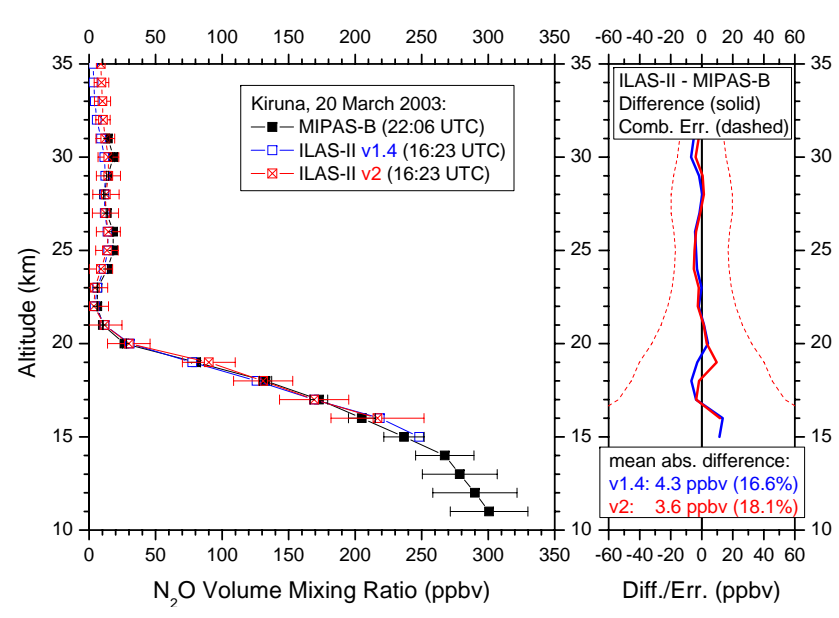

Fig. 2. Comparison of $\mathrm{N}_{2} \mathrm{O}$ profiles as measured by MIPAS-B and ILAS-II. Annotation as per Fig. 1.

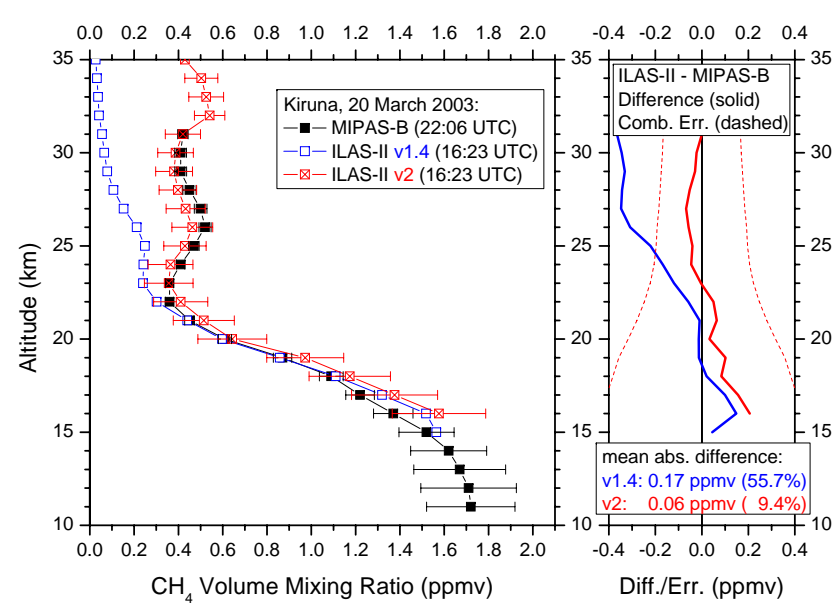

Fig. 3. Comparison of $\mathrm{CH}_{4}$ profiles as measured by MIPAS-B and ILAS-II. Annotation as per Fig. 1.

ures 2 and 3 display the intercomparison of $\mathrm{N}_{2} \mathrm{O}$ and $\mathrm{CH}_{4}$, respectively. Both tracers exhibit very low values in the altitude region around 22 and $23 \mathrm{~km}$ which point to strongly subsided air masses originating from the upper stratosphere or lower mesosphere (Engel et al., 2006). Both ILAS-II data versions reproduce the $\mathrm{N}_{2} \mathrm{O}$ profile observed by MIPAS-B very well. Differences are clearly inside the combined errors and mean absolute deviations over all coincident altitudes amount only about $4 \mathrm{ppbv}(\sim 17 \%)$ whereas the mean deviation even amounts only $-0.1 \mathrm{ppbv}(-11 \%)$ for the version 2 data.

Small differences inside the combined error limits are also obvious when looking at the $\mathrm{CH}_{4}$ comparison with the ILASII version 2 data. The negative bias visible in the version 1.4 data above $22 \mathrm{~km}$ has vanished in the newer data version such that the mean absolute difference diminished to $0.06 \mathrm{ppmv}$ (9.4\%). A positive bias for $\mathrm{CH}_{4}$, which is slightly increasing 


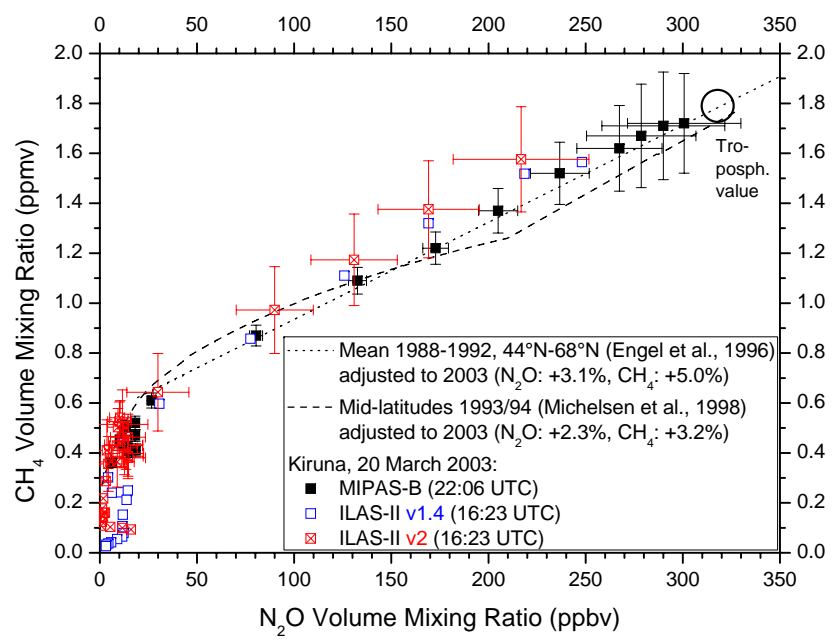

Fig. 4. $\mathrm{N}_{2} \mathrm{O}-\mathrm{CH}_{4}$ correlations as measured by MIPAS-B and ILASII (ILAS-II error bars for $\mathrm{CH}_{4}$ values less than 0.3 ppmv are omitted for clarity). Trend-corrected reference correlations observed by other instruments (in-situ, Engel et al., 1996, and Atmospheric Trace Molecule Spectroscopy Experiment, Michelsen et al., 1998) are shown for comparison. The Northern Hemispheric tropospheric correlation value of 2003 is marked by a black circle.

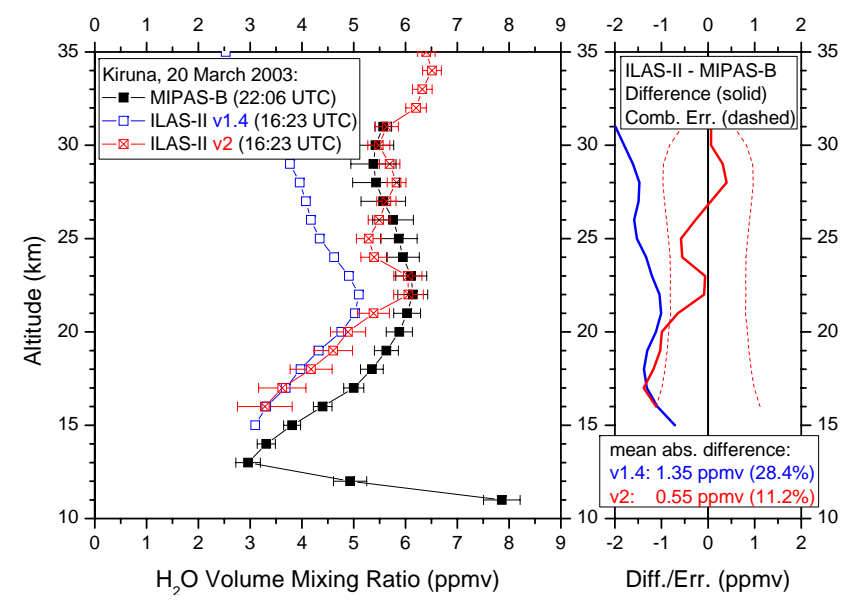

Fig. 5. Comparison of $\mathrm{H}_{2} \mathrm{O}$ profiles as measured by MIPAS-B and ILAS-II. Annotation as per Fig. 1.

downwards, is visible below $23 \mathrm{~km}$. Anyhow, the intercomparison of $\mathrm{N}_{2} \mathrm{O}$ and $\mathrm{CH}_{4}$ confirms that MIPAS-B and ILASII actually sounded air masses with similar characteristics.

Measured $\mathrm{N}_{2} \mathrm{O}-\mathrm{CH}_{4}$ relationships serve as selfconsistency checks since they are not influenced by any mismatch of air masses with different degree of subsidence. Both measured correlations (see Fig. 4), ILAS-II and MIPAS-B, are quite close to the standard relationships deduced by Engel et al. (1996) and Michelsen et al. (1998) after trend-correction to the year 2003 taking into account mean increase rates of $\mathrm{CH}_{4}$ and $\mathrm{N}_{2} \mathrm{O}$. The positive bias in the ILAS-II $\mathrm{CH}_{4}$ version 2 data in the lowermost stratosphere

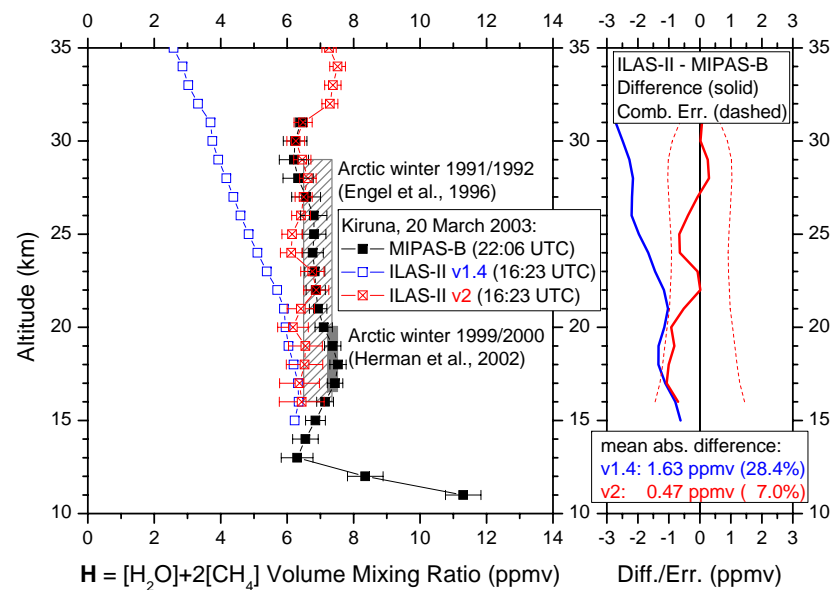

Fig. 6. Hydrogen budget $\mathrm{H}=\left[\mathrm{H}_{2} \mathrm{O}\right]+2\left[\mathrm{CH}_{4}\right]$ as measured by MIPAS-B and ILAS-II. Balloon-borne observations (hatched grey bar) performed by Engel et al. (1996) and aircraft measurements (solid grey bar) carried out by Herman et al. (2002) are shown for comparison.

(cf. Fig. 3) yields to values which are slightly above the standard $\mathrm{N}_{2} \mathrm{O}-\mathrm{CH}_{4}$ correlations.

\subsection{Water vapour and hydrogen budget}

$\mathrm{H}_{2} \mathrm{O}$ profiles measured by MIPAS-B and ILAS-II are presented in Fig. 5. The strong vertical gradient in the MIPASB profile above the hygropause at $13 \mathrm{~km}$ reflects the subsidence of air masses in the polar vortex. The significant negative bias in the ILAS-II version 1.4 data has disappeared in the newer data version above $21 \mathrm{~km}$ and deviations are now within the combined error limits in this altitude region. Griesfeller et al. (2008) show increased $\mathrm{H}_{2} \mathrm{O}$ values from version 1.4 to version 2 even below $21 \mathrm{~km}$ due mainly to the transmittance correction. Although the correction was also applied for the pre-operational measurements in March 2003, it might be not adequate for those measurements.

The oxidation chain of $\mathrm{CH}_{4}$ in the stratosphere produces about two molecules of $\mathrm{H}_{2} \mathrm{O}$. The sum $\mathrm{H}=\left[\mathrm{H}_{2} \mathrm{O}\right]+2\left[\mathrm{CH}_{4}\right]$ is therefore a good measure for the hydrogen budget in the stratosphere because it is a quasi conserved quantity in this altitude region. Figure 6 displays the hydrogen budget as measured by ILAS-II and MIPAS-B in comparison to earlier observations (Engel et al., 1996; Herman et al., 2002). Inferred MIPAS-B volume mixing ratios are quite close to these observations. Above $21 \mathrm{~km}$ the agreement between MIPAS-B and ILAS-II data version 2 is pretty good. The negative bias of up to $1 \mathrm{ppmv}$ in the ILAS-II data below this altitude is caused by the large negative bias in $\mathrm{H}_{2} \mathrm{O}$ which is partly compensated by the small positive $\mathrm{CH}_{4}$ bias in this altitude region. 


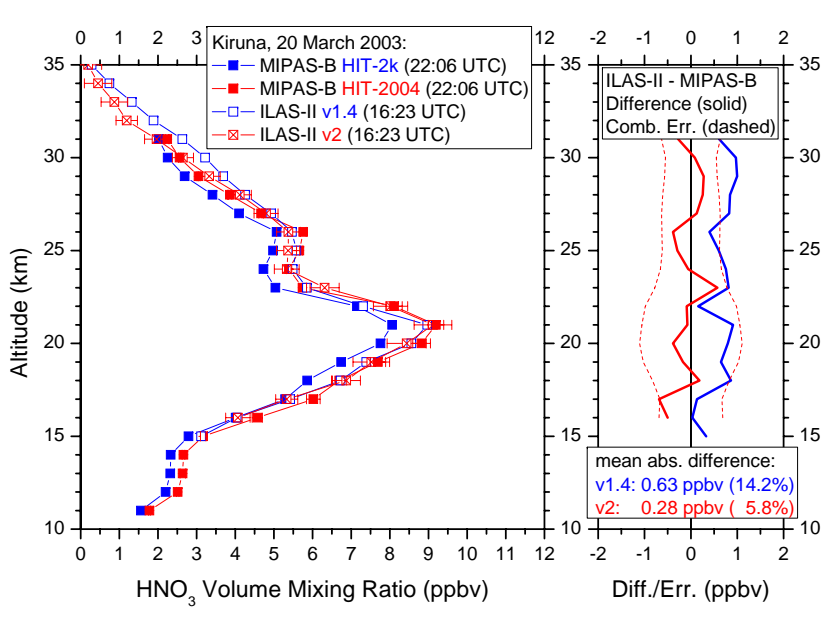

Fig. 7. Comparison of $\mathrm{HNO}_{3}$ profiles as measured by MIPAS-B and ILAS-II. MIPAS-B $\mathrm{HNO}_{3}$ was retrieved with HITRAN 2k (HIT2k) and HITRAN 2004 (HIT-2004) spectroscopic data bases which have been used for the ILAS-II version 1.4 and 2 data retrievals, respectively.

\subsection{Nitrogen species}

Comparison results for the nitrogen reservoir species $\mathrm{HNO}_{3}$ are depicted in Fig. 7. Updates of $\mathrm{HNO}_{3}$ spectroscopy were performed from the HITRAN $2 \mathrm{k}$ to the HITRAN 2004 spectroscopic database (Rothman et al., 2005). Hence, MIPAS$B$ retrieval calculations have been carried out with the same spectroscopic data base that was used for the ILAS-II data analysis. The shape of the profiles observed by both instruments is very similar, including the dip at $24 \mathrm{~km}$. While there is a small positive bias visible in the ILAS-II version 1.4 data, this bias completely disappears in the new version 2 data. Residual differences between ILAS-II and MIPAS-B are now very small (mean absolute difference less than $6 \%$; mean difference less than $-2 \%$ ).

The comparison for the temporary chlorine and nitrogen reservoir species $\mathrm{ClONO}_{2}$ is shown in Fig. 8. The profile shape measured by MIPAS-B exhibiting high amounts of $\mathrm{ClONO}_{2}$ of up to $2.3 \mathrm{ppbv}$, which are typical for the late arctic winter vortex after passivation of active chlorine, is nicely reproduced by ILAS-II. Except the highest altitude region around $30 \mathrm{~km}$ where some deviations between ILAS-II and MIPAS-B are visible, the agreement between both sensors is excellent. The mean absolute difference is less than $10 \%$.

The comparison of the short-lived nitrogen species $\mathrm{NO}_{2}$ is given in Fig. 9. As for $\mathrm{HNO}_{3}$, spectroscopic $\mathrm{NO}_{2}$ updates in the HITRAN databases had to be taken into account when performing the MIPAS-B retrieval. The molecule $\mathrm{NO}_{2}$ exhibits a strong diurnal variation in the stratosphere and is in photochemical equilibrium with $\mathrm{NO}$ and $\mathrm{N}_{2} \mathrm{O}_{5}$. To balance these temporal variations the MIPAS-B results have been photochemically transferred to the time and location of the ILAS-II observations with the help of the three-dimensional

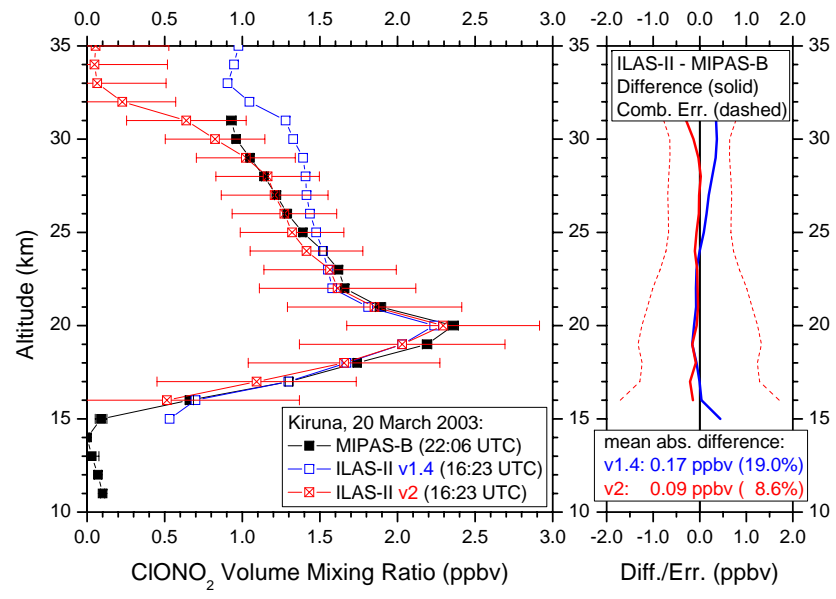

Fig. 8. Comparison of $\mathrm{ClONO}_{2}$ profiles as measured by MIPAS-B and ILAS-II. Annotation as per Fig. 1.

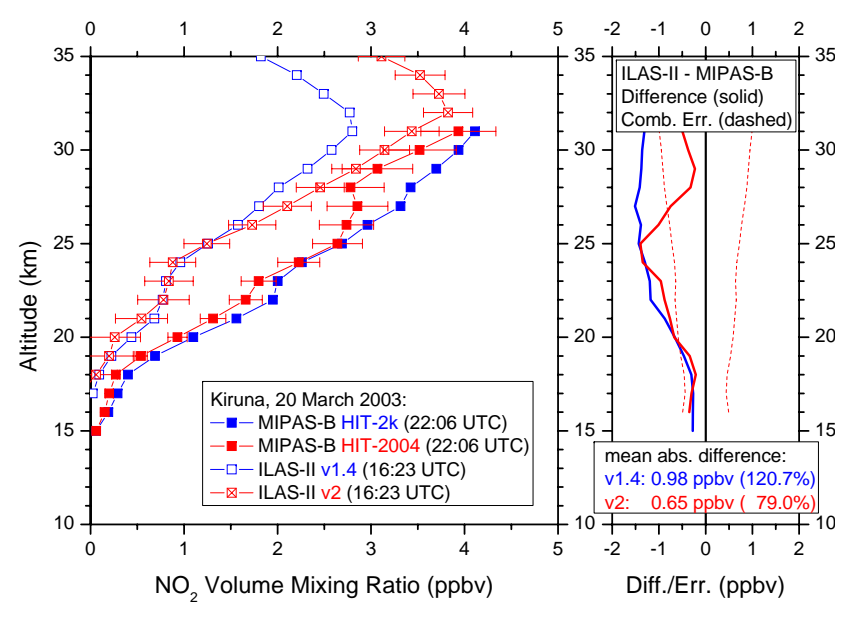

Fig. 9. Comparison of $\mathrm{NO}_{2}$ profiles as measured by MIPAS-B and ILAS-II. MIPAS-B NO 2 was retrieved with HITRAN 2k (HIT2k) and HITRAN 2004 (HIT-2004) spectroscopic data bases which have been used for the ILAS-II version 1.4 and 2 data retrievals, respectively. MIPAS-B mixing ratios have been photochemically corrected to the time and location of ILAS-II observations. Annotation as per Fig. 1.

Chemistry Transport Model (CTM) KASIMA (Karlsruhe Simulation model of the Middle Atmosphere; Kouker et al., 1999). The model was run in a $2.0^{\circ} \times 2.0^{\circ}$ horizontal resolution. The MIPAS-B $\mathrm{NO}_{2}$ values were corrected by scaling them with the altitude dependent $\mathrm{NO}_{2}$ ratio determined from the modelled $\mathrm{NO}_{2}$ profiles for the measurement times and locations of both sensors. In spite of the photochemical correction, a significant negative bias of up to about $1 \mathrm{ppbv}$ is visible regarding the ILAS-II version 2 data. Investigations of the influence of different photolysis rates used in the CTM can only account for about $4 \%$ mean absolute differences in $\mathrm{NO}_{2}$ above $22 \mathrm{~km}$ (Wetzel et al., 2006). It should 
Table 1. Quality of agreement of ILAS-II data versions 1.4 (v1.4) and 2 (v2) compared to MIPAS-B independent observations on 20 March 2003. Results are given for different species; mean absolute difference (MAD), mean difference (MD), comments and ratings (++ very good; + good; o fair; - poor) are summarized. Mean difference values are calculated over all coincident altitudes.

\begin{tabular}{llllllll}
\hline Species & MAD (v1.4) & MAD (v2) & MD (v1.4) & MD (v2) & Comments and ratings & v1.4 & v2 \\
\hline $\mathrm{O}_{3}$ & $11.6 \%$ & $6.3 \%$ & $-10.0 \%$ & $-6.3 \%$ & small negative bias (within comb. errors) & + & + \\
$\mathrm{N}_{2} \mathrm{O}$ & $16.6 \%$ & $18.1 \%$ & $-11.8 \%$ & $-11.1 \%$ & very good agreement & ++ \\
$\mathrm{CH}_{4}$ & $55.7 \%$ & $9.4 \%$ & $-53.0 \%$ & $0.2 \%$ & very good agreement for v2 & ++ \\
$\mathrm{H}_{2} \mathrm{O}$ & $28.4 \%$ & $11.2 \%$ & $-28.4 \%$ & $-9.2 \%$ & negative bias (not for v2 above 21 km) & + & + \\
$\mathrm{HNO}_{3}$ & $14.2 \%$ & $5.8 \%$ & $14.2 \%$ & $-1.6 \%$ & very good agreement for v2 & + \\
$\mathrm{ClONO}_{2}$ & $19.0 \%$ & $8.6 \%$ & $15.4 \%$ & $-8.3 \%$ & very good agreement for v2 & + \\
$\mathrm{NO}_{2}$ & $120.7 \%$ & $79.0 \%$ & $-78.9 \%$ & $-60.0 \%$ & negative bias & + \\
$\mathrm{N}_{2} \mathrm{O} 5$ & - & - & - & - & mostly negative ILAS-II mixing ratios & - & + \\
$\mathrm{CFC}-11$ & $22.7 \%$ & $25.7 \%$ & $14.2 \%$ & $25.7 \%$ & good agreement below 20 km & - \\
$\mathrm{CFC}-12$ & $69.6 \%$ & $84.3 \%$ & $69.6 \%$ & $84.3 \%$ & positive bias & + \\
\hline
\end{tabular}

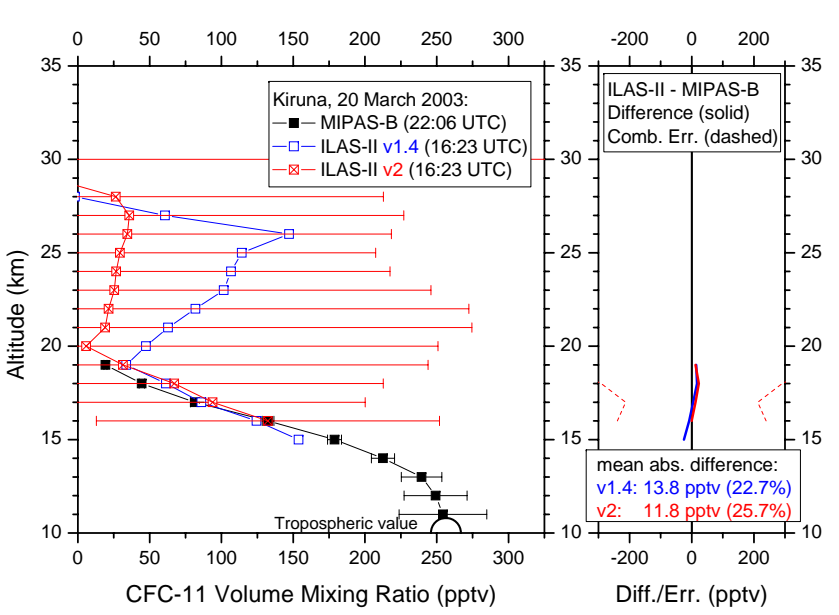

Fig. 10. Comparison of CFC-11 profiles as measured by MIPAS-B and ILAS-II. The Northern Hemispheric tropospheric value of 2003 is marked by a black half circle. Annotation as per Fig. 1 .

be mentioned that no corrections of variations of the solar zenith angle along the line of sight of ILAS-II were performed. This may introduce some inaccuracies in the ILASII $\mathrm{NO}_{2}$ data. Payan et al. (1999) estimated such VMR errors for infrared solar occultation measurements to less than $6 \%$. These effects can therefore only partly help to explain the remaining differences between ILAS-II and MIPAS-B measured quantities (particularly below about $27 \mathrm{~km}$ where the diurnal variation of $\mathrm{NO}_{2}$ decreases). Here, ILAS-II Northern Hemispheric sunrise data are being discussed. In contrast, Randall et al. (2007) used ILAS-II version 2 Southern Hemispheric sunset $\mathrm{NO}_{2}$ data for their studies. They found this data in qualitative agreement with $\mathrm{NO}_{2}$ measured by POAM III, although they also noticed a small negative bias in the ILAS-II mixing ratios compared to the POAM III observations.

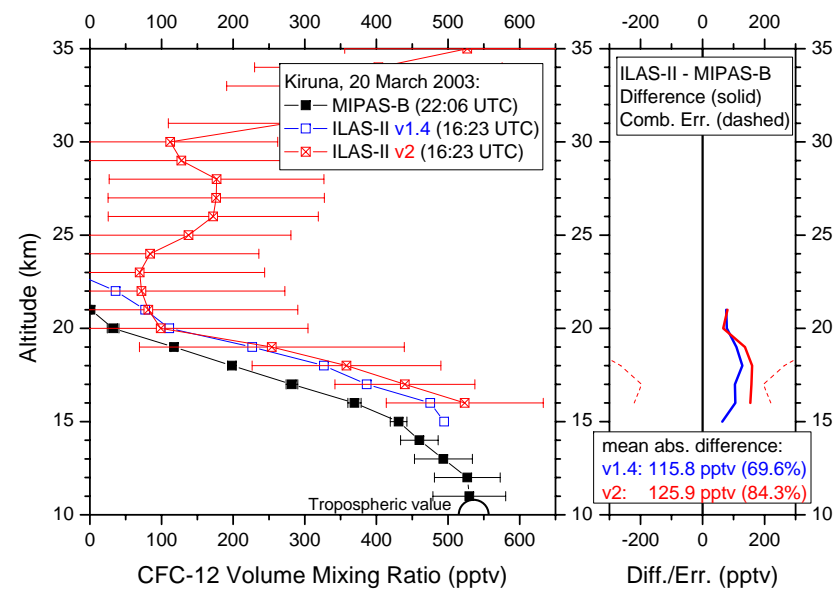

Fig. 11. Comparison of CFC-12 profiles as measured by MIPAS-B and ILAS-II. The Northern Hemispheric tropospheric value of 2003 is marked by a black half circle. Annotation as per Fig. 1 .

As mentioned above, $\mathrm{NO}_{2}$ is also photochemically linked with $\mathrm{N}_{2} \mathrm{O}_{5}$ such that the latter species exhibits a diurnal variation, too. This has to be taken into account when comparing $\mathrm{N}_{2} \mathrm{O}_{5}$ data of both sensors. However, although ILAS-II $\mathrm{N}_{2} \mathrm{O}_{5}$ mixing ratios of the new version 2 have increased compared to the old version 1.4 (leading to a smaller negative bias compared to MIPAS-B) they are still less than zero except at the altitude region near $30 \mathrm{~km}$. Hence, a sound comparison to MIPAS-B measured $\mathrm{N}_{2} \mathrm{O}_{5}$ quantities is not yet meaningful for this molecule.

\subsection{Chlorofluorocarbons}

Figures 10 and 11 show the retrieved volume mixing ratios of the important chlorine source gases CFC-11 $\left(\mathrm{CCl}_{3} \mathrm{~F}\right)$ and $\mathrm{CFC}-12\left(\mathrm{CCl}_{2} \mathrm{~F}_{2}\right)$. For the species CFC-11, the agreement between ILAS-II and MIPAS-B is pretty good below 
$20 \mathrm{~km}$ altitude. The increase of ILAS-II CFC-11 mixing ratios above $20 \mathrm{~km}$ which is not visible in the MIPAS-B data is far less pronounced in the newer data version and not significant with regard to the large error bars which seem to be overestimated for this molecule.

An increase of volume mixing ratios above $23 \mathrm{~km}$ is also seen in the new ILAS-II data version of the retrieved CFC-12 profile. Such an increase does not appear to be realistic because mixing ratios reach more than $500 \mathrm{pptv}$ at $35 \mathrm{~km}$ which corresponds to tropospheric values. The increase is also not visible in the MIPAS-B data. Below $22 \mathrm{~km}$ a significant positive bias of at least $100 \mathrm{pptv}$ in both ILAS-II data versions is clearly visible.

\section{Conclusions}

The intercomparison of ILAS-II trace species to MIPAS-B measurements has shown that the overall agreement between both sensors has significantly been improved for the new ILAS-II (Northern Hemispheric sunrise) data version 2 in comparison to the older version 1.4. This is fully consistent with the recent findings of Griesfeller et al. (2008) who compared ILAS-II $\mathrm{H}_{2} \mathrm{O}, \mathrm{N}_{2} \mathrm{O}, \mathrm{CH}_{4}, \mathrm{O}_{3}, \mathrm{HNO}_{3}$, and $\mathrm{ClONO}_{2}$ data to MIPAS on ENVISAT. A summary of the assessment of the individual comparisons is given in Table 1. For the species $\mathrm{O}_{3}, \mathrm{~N}_{2} \mathrm{O}, \mathrm{CH}_{4}, \mathrm{HNO}_{3}, \mathrm{ClONO}_{2}$, and CFC-11 a good to excellent agreement between MIPAS-B and ILAS-II version 2 data could be identified in the compared altitude region between 16 and $31 \mathrm{~km}$. Hence, the new data version 2 of these molecules appears to be very useful for scientific studies. For the species $\mathrm{H}_{2} \mathrm{O}$, a good agreement has been achieved for altitudes above $21 \mathrm{~km}$ (version 2 data) while for altitudes below a significant negative bias of about $1 \mathrm{ppmv}$ is still obvious. ILAS-II $\mathrm{NO}_{2}$ and $\mathrm{N}_{2} \mathrm{O}_{5}$ are widely characterized by negative biases compared to MIPAS-B results although the magnitude of the biases has decreased from ILAS-II version 1.4 to version 2 data. In contrast, CFC-12 is still marked by a positive bias in comparison to the balloonborne observations. Hence, these latter gases cannot be assumed to be validated at the present time. Reasons for these observed deviations are still speculative and need further investigations. It should be mentioned that these gases provide only minor contributions to the transmittance spectrum in the low-resolution ILAS-II infrared channels and their spectral signatures are overlapped by strongly interfering gases. Hence, their detection and analysis is quite difficult given the ILAS-II spectral resolution.

Acknowledgements. We are grateful to the Centre National d'Etudes Spatiales (CNES) launching team for excellent balloon operations, the Esrange team of the Swedish Space Corporation (SSC) for logistical support and the Free University of Berlin for meteorological support (especially K. Grunow). This work was funded in part by the Bundesministerium für Bildung und Forschung (BMBF), the European Space Agency (ESA), and the
Global Environment Research Fund (GERF) of the Ministry of the Environment, Japan (MOE).

Edited by: U. Pöschl

\section{References}

Cortesi, U., Lambert, J. C., De Clercq, C., Bianchini, G., Blumenstock, T., Bracher, A., Castelli, E., Catoire, V., Chance, K. V., De Mazière, M., Demoulin, P., Godin-Beekmann, S., Jones, N., Jucks, K., Keim, C., Kerzenmacher, T., Kuellmann, H., Kuttippurath, J., Iarlori, M., Liu, G. Y., Liu, Y., McDermid, I. S., Meijer, Y. J., Mencaraglia, F., Mikuteit, S., Oelhaf, H., Piccolo, C., Pirre, M., Raspollini, P., Ravegnani, F., Reburn, W. J., Redaelli, G., Remedios, J. J., Sembhi, H., Smale, D., Steck, T., Taddei, A., Varotsos, C., Vigouroux, C., Waterfall, A., Wetzel, G., and Wood, S.: Geophysical validation of MIPAS-ENVISAT operational ozone data, Atmos. Chem. Phys., 7, 4807-4867, 2007, http://www.atmos-chem-phys.net/7/4807/2007/.

Engel, A., Schiller, C., Schmidt, U., Borchers, R., Ovarlez, H., and Ovarlez, J.: The total hydrogen budget in the Arctic winter stratosphere during the European Arctic Stratospheric Ozone Experiment, J. Geophys. Res., 101, 14 495-14 503, 1996.

Engel, A., Möbius, T., Haase, H.-P., Bönisch, H., Wetter, T., Schmidt, U., Levin, I., Reddmann, T., Oelhaf, H., Wetzel, G., Grunow, K., Huret, N., and Pirre, M.: Observation of mesospheric air inside the arctic stratospheric polar vortex in early 2003, Atmos. Chem. Phys., 6, 267-282, 2006, http://www.atmos-chem-phys.net/6/267/2006/.

Friedl-Vallon, F., Maucher, G., Kleinert, A., Lengel, A., Keim, C., Oelhaf, H., Fischer, H., Seefeldner, M., and Trieschmann, O.: Design and characterization of the balloon-borne Michelson Interferometer for Passive Atmospheric Sounding (MIPAS-B2), Appl. Optics, 43, 3335-3355, 2004.

Griesfeller, A., von Clarmann, T., Griesfeller, J., Höpfner, M., Milz, M., Nakajima, H., Steck, T., Sugita, T., Tanaka, T., and Yokota, T.: Intercomparison of ILAS-II Version 1.4 and Version 2 target parameters with MIPAS-Envisat measurements, Atmos. Chem. Phys., 8, 825-843, 2008, http://www.atmos-chem-phys.net/8/825/2008/.

Herman, R. L., Drdla, K., Spackman, J. R., Hurst, D. F., Popp, P. J., Webster, C. R., Romashkin, P. A., Elkins, J. W., Weinstock, E. M., Gandrud, B. W., Toon, G. C., Schoeberl, M. R., Jost, H., Atlas, E. L., and Bui, T. P.: Hydration, dehydration, and the total hydrogen budget of the 1999/2000 winter Arctic stratosphere, J. Geophys. Res., 108(D5), 8320, doi:10.1029/2001JD001257, 2002.

Höpfner, M., Oelhaf, H., Wetzel, G., Friedl-Vallon, F., Kleinert, A., Lengel, A., Maucher, G., Nordmeyer, H., Glatthor, N., Stiller, G., von Clarmann, T., Fischer, H., Kröger, C., and Deshler, T.: Evidence of scattering of tropospheric radiation by PSCs in mid-IR limb emission spectra: MIPAS-B observations and KOPRA simulations, Geophys. Res. Lett., 29(8), 1278, doi:10.1029/2001GL014443, 2002.

Höpfner, M., von Clarmann, T., Fischer, H., Funke, B., Glatthor, N., Grabowski, U., Kellmann, S., Kiefer, M., Linden, A., Milz, M., Steck, T., Stiller, G. P., Bernath, P., Blom, C. E., Blumenstock, Th., Boone, C., Chance, K., Coffey, M. T., Friedl-Vallon, F., Griffith, D., Hannigan, J. W., Hase, F., Jones, N., Jucks, K. 
W., Keim, C., Kleinert, A., Kouker, W., Liu, G. Y., Mahieu, E., Mellqvist, J., Mikuteit, S., Notholt, J., Oelhaf, H., Piesch, C., Reddmann, T., Ruhnke, R., Schneider, M., Strandberg, A., Toon, G., Walker, K. A., Warneke, T., Wetzel, G., Wood, S., and Zander, R.: Validation of MIPAS $\mathrm{ClONO}_{2}$ measurements, Atmos. Chem. Phys., 7, 257-281, 2007,

http://www.atmos-chem-phys.net/7/257/2007/.

Kouker, W., Langbein, I., Reddmann, T., and Ruhnke, R.: The Karlsruhe simulation model of the middle atmosphere (KASIMA), version 2, Rep. FZKA 6278, Forschungszentrum Karlsruhe GmbH, Karlsruhe, Germany, 1999.

Michelsen, H. A., Manney, G. L., Gunson, M. R., and Zander, R.: Correlations of stratospheric abundances of $\mathrm{NO}_{\mathrm{y}}, \mathrm{O}_{3}, \mathrm{~N}_{2} \mathrm{O}$, and $\mathrm{CH}_{4}$ derived from ATMOS measurements, J. Geophys. Res., 103, 28 347-28 359, 1998.

Nakajima, H., Sugita, T., Yokota, T., Ishigaki, T., Mogi, Y., Araki, N., Waragai, K., Kimura, N., Iwazawa, T., Kuze, A., Tanii, J., Kawasaki, H., Horikawa, M., Togami, T., Uemura, N., Kobayashi, H., and Sasano, Y.: Characteristics and performance of the Improved Limb Atmospheric Spectrometer-II (ILAS-II) on board the ADEOS-II satellite, J. Geophys. Res., 111, D11S01, doi:10.1029/2005JD006334, 2006.

Payan, S., Camy-Peyret, C., Jeseck, P. Hawat, T., Pirre, M., Renard, J.-B., Robert, C., Lefèvre, F., Kanzawa, H., and Sasano, Y.: Diurnal and nocturnal distribution of stratospheric $\mathrm{NO}_{2}$ from solar and stellar occultation measurements in the Arctic vortex: Comparison with models and ILAS satellite measurements, J. Geophys. Res., 104, 21 585-21 593, 1999.

Randall, C. E., Harvey, V. L., Singleton, C. S., Bailey, S. M., Bernath, P. F., Codrescu, M., Nakajima, H., and Russell III, J. M.: Energetic particle precipitation effects on the Southern Hemisphere stratosphere in 1992-2005, J. Geophys. Res., 112, D08308, doi:10.1029/2006JD007696, 2007.

Ridolfi, M., Blum, U., Carli, B., Catoire, V., Ceccherini, S., Claude, H., De Clercq, C., Fricke, K. H., Friedl-Vallon, F., Iarlori, M., Keckhut, P., Kerridge, B., Lambert, J.-C., Meijer, Y. J., Mona, L., Oelhaf, H., Pappalardo, G., Pirre, M., Rizi, V., Robert, C., Swart, D., von Clarmann, T., Waterfall, A., and Wetzel, G.: Geophysical validation of temperature retrieved by the ESA processor from MIPAS/ENVISAT atmospheric limb-emission measurements, Atmos. Chem. Phys., 7, 4459-4487, 2007, http://www.atmos-chem-phys.net/7/4459/2007/.

Rothman, L. S., Barbe, A., Benner, D. C., et al.: The HITRAN molecular spectroscopic database: edition of 2000 including updates through 2001, J. Quant. Radiat. Transfer, 82, 5-44, 2003.

Rothman, L. S., Jacquemart, D., Barbe, A., et al.: The HITRAN 2004 molecular spectroscopic database, J. Quant. Spectrosc. Radiat. Transfer, 96, 139-204, 2005.
Sasano, Y., Suzuki, M., Yokota, T., and Kanzawa, H.: Improved Limb Atmospheric Spectrometer (ILAS) for stratospheric ozone layer measurements by solar occultation technique, Geophys. Res. Lett., 26, 197-200, 1999.

Stiller, G. P., von Clarmann, T., Funke, B., Glatthor, N., Hase, F., Höpfner, M., and Linden, A.: Sensitivity of trace gas abundances retrievals from infrared limb emission spectra to simplifying approximations in radiative transfer modeling, J. Quant. Spectrosc. Radiat. Transfer, 72(3), 249-280, 2002.

Tanaka, T., Nakajima, H., Sugita, T., Ejiri, M. K., Irie, H., Saitoh, N., Terao, Y., Kawasaki, H., Usami, M., Yokota, T., Kobayashi, H., and Sasano, Y.: Tangent height registration method for the Version 1.4 data retrieval algorithm of the solar occultation sensor ILAS-II, Appl. Optics, 46, 7196-7201, 2007.

Wang, D. Y., Höpfner, M., Blom, C. E., Ward, W. E., Fischer, H., Blumenstock, T., Hase, F., Keim, C., Liu, G. Y., Mikuteit, S., Oelhaf, H., Wetzel, G., Cortesi, U., Mencaraglia, F., Bianchini, G., Redaelli, G., Pirre, M., Catoire, V., Huret, N., Vigouroux, C., De Mazière, M., Mahieu, E., Demoulin, P., Wood, S., Smale, D., Jones, N., Nakajima, H., Sugita, T., Urban, J., Murtagh, D., Boone, C. D., Bernath, P. F., Walker, K. A., Kuttippurath, J., Kleinböhl, A., Toon, G., and Piccolo, C.: Validation of MIPAS $\mathrm{HNO}_{3}$ operational data, Atmos. Chem. Phys., 7, 4905-4934, 2007 , http://www.atmos-chem-phys.net/7/4905/2007/.

Wetzel, G., Oelhaf, H., Friedl-Vallon, F., Kleinert, A., Lengel, A., Maucher, G., Nordmeyer, H., Ruhnke, R., Nakajima, H., Sasano, Y., Sugita, T., and Yokota, T.: Intercomparison and validation of ILAS-II version 1.4 target parameters with MIPAS-B measurements, J. Geophys. Res., 111, D11S06, doi:10.1029/2005JD006287, 2006.

Wetzel, G., Bracher, A., Funke, B., Goutail, F., Hendrick, F., Lambert, J.-C., Mikuteit, S., Piccolo, C., Pirre, M., Bazureau, A., Belotti, C., Blumenstock, T., De Mazière, M., Fischer, H., Huret, N., Ionov, D., López-Puertas, M., Maucher, G., Oelhaf, H., Pommereau, J.-P., Ruhnke, R., Sinnhuber, M., Stiller, G., Van Roozendael, M., and Zhang, G.: Validation of MIPAS-ENVISAT $\mathrm{NO}_{2}$ operational data, Atmos. Chem. Phys., 7, 3261-3284, 2007, http://www.atmos-chem-phys.net/7/3261/2007/.

Yokota, T., Nakajima, H., Sugita, T., Tsubaki, H., Itou, Y., Kaji, M., Suzuki, M., Kanzawa, H., Park, J. H., and Sasano, Y.: Improved Limb Atmospheric Spectrometer (ILAS) data retrieval algorithm for Version 5.20 gas profile products, J. Geophys. Res., 107, 8216, doi:10.1029/2001JD000628, 2002. 